\title{
FORMING LEARNING IDENTITIES IN HIGHER EDUCATION IN SWEDEN
}

\author{
CAMILLA THUNBORG, AGNIESZKA BRON, EVA EDSTRÖM \\ Stockholm University, Sweden
}

\section{ABSTRACT}

The aim of this paper is to deepen understanding of the forming of learning identities amongst non-traditional students in Higher Education (HE). Learning identities are related to how actors experience themselves as learners in relation to their previous experiences, social background and different academic cultures and contexts. The forming of learning identities is a part of the forming of overall identities, and we use three identity types for our analysis: multiple integrated, floating and adopted. The study is built on biographical interviews with six students (chosen from a pool of 100) and 37 semi-structured interviews with staff from three HE institutions in Sweden. The results show that non-traditional students tend to feel like outsiders, and that this seems to be related to class and age rather than ethnicity and gender. Nevertheless, they form different identities and learning identities. Those forming a multiple integrated identity define themselves as learners and sometimes even as independent learners, while students forming an adopted identity seem to identify themselves with the academy generally. The learning identity they form is that of a "good student". Students forming a floating identity have difficulty de-
\end{abstract}

fining themselves within the academy. Finally, some students seem to form a pragmatic identity, identifying with their future profession rather than the academy. In doing this an instrumental learning identity is formed. In the academy and in the case of lecturers, status is related to research orientation, whereas in the case of students, the value of education seems to be related to gaining employment. This creates tensions in the HE system.

Keywords: Learning identities, Higher education in Sweden, non-traditional students, biographical interviews, academic culture

\section{FORMING LEARNING IDENTITIES IN HIGHER EDUCATION IN SWEDEN}

In the EU Lifelong Learning Programme project (www.ranlhe.dsw.edu.pl), we have identified and studied factors that promote and/or constrain nontraditional students' access, retention and non-completion in Higher Education (HE) in seven countries. This paper is concerned with non-traditional students in Sweden.

\begin{abstract}
CAMILLA THUNBORG has a PhD in Education and is Associate Professor at Stockholm University. She has pursued an interest in issues of learning since the 1990s and has a special interest in the forming and changing of identities in different settings such as higher education, professions and workplaces. Her research and teaching focus on two research areas: Adult Education and Organisational Pedagogy.
\end{abstract}

Professor Dr. AGNIESZKA BRON holds the Chair of Education at Stockholm University, Sweden. She has published extensively on subjects including biographical learning (ethnicity, gender, informal learning and work), and comparative studies (blue-collar workers' access to post-secondary education, and non-traditional students). Her research includes engagement in several European projects concerning mature students in higher education.

EVA EDSTRÖM works as a Lecturer at the School of Education, Culture and Communication (UKK), Mälardalen University, Sweden. She holds a Master of Social Science degree with an education major awarded in July 2009 and a first Bachelor of Sociology and Education degree from Stockholm University. At present she is teaching in Adult Education. 
The Swedish HE system has gone through many changes and reforms during the past 60 years. The reforms aimed to open access to HE for a new group: so-called non-traditional students, typically students from working-class homes, students from a nonSwedish ethnic background, mature students, women and students with disabilities. During the 1990s HE institutions were expanded, partly by integrating several professional programmes alongside general academic degrees. The composition of the Swedish student body has changed as a result of HE policy changes and reforms (Bron \& Lönnheden 2004). In the academic year 2007/08, 57 per cent of entrants $(87,000)$ were female (Högskoleverket, 2007). The number of students from a non-Swedish ethnic background has increased, but there remain differences between ethnic groups; this is also related to class. Students from a working-class background are still underrepresented (Thunborg \& Bron, in press). Moreover, the drop-out rate in Sweden is the highest in Europe. Only about 40 per cent of students end up with a degree after seven years of study. Does this have to do with changes in the student body? There is no clear evidence that the high drop-out rate is related to that. Leathwood (2006) shows, for example, that a discourse of the independent learner is present in higher education, which is inappropriate for the majority of students in a mass higher education system.

Clashes between non-traditional learners and the academy have been identified in different ways in research on participation in higher education. Coronel Llamas (2006) shows that there are several techniques used in higher education to control and discipline students towards the discourse of the "good student". Collier \& Morgan (2008) find differences in the interpretation of faculty expectations between traditional college students and students who were the first of their family to progress to HE study. Quinn (2004) shows that working-class students experience a tension between their class identity and the middle-class study culture. They also see themselves as facing the paradox of a double failure: they are undertaking study in order to get a better job, but should they fail and drop out they may end up in a worse position than if they had never entered higher education.

Mature students also experience culture clashes when entering HE. West (1996) shows, for example, that perspectives developed through human experience, adult learning, the problems of adult learners and ways of communicating are underdeveloped in academic institutions, and that this has consequences for mature students. Murphy \& Fleming (2000) identified a clash between the "college knowledge" presented by the universities and "common knowledge" related to the life experience of mature students. Bron \& Lönnheden (2004) show that mature students in social sciences and humanities develop a new way of participating in society. They view their experience of $\mathrm{HE}$ as a democratic process in which they gained the self-confidence required for their own life and learning. Previous research on non-traditional students has taken a special interest in issues of class and age. This paper also deals with ethnicity as part of the understanding of non-traditional learners in HE. We claim that an understanding of how non-traditional students form learning identities in HE is important in order to grasp the changes in HE. We are also interested in the role of $\mathrm{HE}$ for non-traditional learners in Sweden. Our interest in these students is justified by the relative difficulties that we see them to be facing in accessing and completing their studies.

\section{THE AIM OF THE PAPER}

The aim of this paper is to deepen understanding of the forming of learning identities amongst non-traditional HE students in Sweden. The aim is further specified in the following questions:

1. What struggles do non-traditional students experience in their forming of a learning identity in HE?

2. How are these struggles related to issues of ethnicity, age, class and gender on the one hand, and their participation in HE on the other?

3. How are students' learning identities related to the different expectations and contexts of academic cultures?

\section{LEARNING IDENTITIES}

Identities can be seen to be formed in the relation between agency and structure, assuming an individual to be the acting agent (Giddens, 1984). Individual agents define themselves in relation and with reference to other agents, contexts and previous experiences (Mead, 1934). Identities are formed as part of a relation between the active 'I' and the socialised 'me' (Ibid.) Identities are also related to social background, i.e. class, ethnicity, gender and age. We earlier found three explanatory types of identity formation in HE: integrated multiple, floating and adopted. An integrated multiple identity is a definition of oneself as a multiple person with different life experiences that exist parallel to each other and are at the same time integrated. A floating identity is present in stories of struggles between "who I am" and "who I am supposed to be" in relation to different experiences and expectations. Adults with a floating identity seem to be insecure and to commute from one identity to another; they have different "me" identities. Finally, an adopted identity is found in stories in which different 
backgrounds and experiences are hidden behind a coherent presentation of one single identity related to each new situation. The three types of identity could be seen as temporary in relation to different situations in life (Bron, Edström \& Thunborg, 2010).

A learning identity is specifically related to "how actors experience themselves as learners". Becoming a learner in $\mathrm{HE}$ is discussed in terms of how students relate to themselves as agents, structured by their social background and previous learning experiences; how they relate to the specific educational academic institution; and their expectations regarding how to be a good student in that context. In relation to expectations related to being a good student, a contrast has been found between being a learning failure or an instrumental learner (Thunborg \& Edström, 2010).

Changes in identities are conditioned by learning crises. Bron (2000) uses the concept of "floating" to understand identity crises. The floating concept relates to an experience of being fragmented, lacking any feeling of having a past and being unable to create a future. Floating is experienced when people are confronted with a new culture as a consequence of a change in their life setting, such as moving from one country to another or from the countryside to the city, or changing education or occupation. This paper is about struggles in forming a learning identity. In forming and changing learning identities, people experience struggles in relation to who they are in a specific situation or context. Transitional space, first defined by Winnicott (1971), is a concept through which to understand the exploration process of selfnegotiating that learners are involved in when trying to form and change their identity in relation to others. This concept is used in biographical research (Merrill \& West, 2009), in which there is a time for reflection and self-negotiation and struggles can be discovered and understood. What is more, it seems to indicate a difference between the formation of a learning identity as an academic or in relation to a profession (Edström, 2009).

\section{ACADEMIC CULTURE}

Sociological theorising on academic culture takes into consideration Becher's (1989) distinctions between hard and soft and applied and pure disciplines. The dynamics of cultures and sub-cultures in academia are, moreover, theorised with the help of Bourdieu's concept of habituses of academics (Bourdieu, 1984). Depending on the discipline's position in the field, it is possible to discover exclusive, ambivalent, pragmatic and inclusive habitus (see Alheit, n/d). Academic culture can be presented through policy changes within $\mathrm{HE}$, both within academia and in relation to access and student intake.
The academic culture in Swedish HE is based on two traditions: the modern research university of Humboldt tradition and the Anglo-Saxon teaching university (Bron \& Talerud, 2005). The first has as its main aim the production of knowledge and research, and educating students to become knowledge seekers and researchers. The other is generally teachingorientated and seeks to produce professionals who can serve society. The technology, medicine, social and care, law and teaching professions are the main concern in this approach. To understand Swedish HE is to see how these two traditions are combined and how they sometimes contradict each other.

The change in staff composition - from traditional professors and assistants when universities were few and $\mathrm{HE}$ was directed toward research and the elite (in a German style), to staff more suited to teaching universities which are open to wider groups - had an impact on the culture of HE institutions. In 1958 the lecturer position (open to holders of a $\mathrm{PhD}$ ) for teaching undergraduates was introduced; professors, meanwhile, were meant to lead research and supervise $\mathrm{PhD}$ students. This tradition is still present in Swedish HE and is supported by non-academic institutions, previously without any research tradition, which have become part of HE. At the same time another paradigm, in which both research and teaching are combined, became the core of academic culture in more traditional institutions. This creates some tensions between staff in professionally orientated institutions/programmes and those in academic/ research-orientated institutions.

\section{METHOD}

This paper is based on a case study of three institutions in Sweden which are regarded as 'old' universities: Stockholm University (SU), Karolinska Institutet (KI) and the Royal Institute of Technology (KTH). Furthermore, it focuses on biographical interviews with six HE students from a non-Swedish ethnic background. They were chosen from a sample of about 100 interviews. Finally, 37 semi-structured interviews with staff - professors and lecturers at the three institutions - were undertaken; they are used here for the analysis of institutions and staff culture.

The biographical data was analysed with a grounded theory approach by means of open and selective coding. Two main categories - struggles and identity - were identified in the material; this opened up the data for further identification and understanding of learning in HE. With this in mind, the specific analysis in this paper consists of five steps. First of all, struggles in learning in HE were identified; second, these struggles were related to each person's social background and previous life experiences; third, 
the struggles were related to our previously defined explanatory types of identity, explained in the theoretical background; fourth, academic cultures and disciplines, students' expectations and struggles expressed in staff interviews were analysed in relation to both Becher's distinctions concerning academic culture and the previously defined identity types. Finally, the formation of student learning identities was analysed by relating the students' and staff's perspectives to each other.

\section{VIGNETTES}

In this section we present vignettes of the three institutions and the six students in the study.

\section{Institutions}

We conducted our research in three institutions, all situated in Stockholm: Karolinska institutet (KI), Stockholm University (SU) and the Royal Institute of Technology (KTH).

\section{Karolinska Institutet (KI)}

KI was initially founded as a training centre for army surgeons in 1810. Nowadays it is one of Europe's largest medical universities. According to the 2009 Academic Ranking of World Universities, it is the highest ranked university in Clinical Medicine and Pharmacy in Europe, eighth in the world, and the best ranked university in Sweden. KI has a tradition of applied sciences, which has gradually become more research and theory-orientated (applied/hard). In 2006, it had 5,851 undergraduate and master's degree students (77 per cent women, 23 men) and 2,801 doctoral students. Of the freshers, 44 per cent were younger than 25. Eighty-six per cent were participating in programmes and 14 per cent in separate courses, 21 per cent had a working-class background, 32 per cent had an immigrant background and 37 per cent had parents who had achieved a higher level of education (Högskoleverket, 2007). Of the professors, 17 per cent were female and 83 per cent male. KI specialises in Medicine and Nursing and offers 23 different educational programmes, most of them professional.

At KI we selected two programmes: Biomedicine and Physiotherapy. The first includes a combination of pure/hard disciplines, has an exclusive habitus and has no clear job profile. The second includes applied/ hard disciplines with a pragmatic habitus where students are trained into a clearly defined profession, which can lead to a medium-level care job. Both programmes have many applicants and are difficult to access.

\section{Stockholm University (SU)}

In 1878, the Stockholm University College started operations. It staged a series of public lectures in natural sciences - a tradition still supported by yearly lectures that are open to the public. In 1904 the college became an official degree-granting institution, and by 1960 it had received university status. Its status and reputation is based on its being the largest university in the country, as well as the capital city's university. It has a tradition of free research disciplines (natural science and humanities: pure/ hard, and pure/soft) with fifteen main profiles in Natural, Humanities and Social Science (www.su.se/ pub/jsp/polopoly.jsp?d=3926). In 2006, it had 39,000 students - 36 per cent in Social Sciences, 27 per cent in Humanities, 12 per cent in Law and in Science, seven per cent studying various other subjects and six percent in Technical subject areas. 60 per cent of the students were women, 43 per cent were under 25 years old, 76 per cent were enrolled in courses and 24 per cent were involved in study programmes (www. su.se/pub/jsp/polopoly.jsp?d=3807\& a=13337). Of the professors, 22 per cent were female and 78 per cent male.

We selected two programmes at SU: Biology (including chemistry) and Social Work. The first is a hard/ pure science, with an exclusive habitus and without a clear job description, which is easily accessible. The second is based on soft/applied disciplines with an inclusive habitus and a clear job description, and is harder to access.

\section{The Royal Institute of Technology (KTH)}

KTH was founded in 1827 as Sweden's first polytechnic institution and is a leading technical university in Europe. It is highly respected, especially in the domains of technology and natural sciences, with a tradition of applied sciences which have gradually become more research and theory-orientated (applied/hard). The Institute offers about 70 different educational programmes, the two largest being Architectural and Civil Engineering, which account for more than 51 per cent of students. In 2006 the Institute had 12,093 undergraduate and master's degree students and 1,444 doctoral students. KTH had 2,802 employees (www.kth.se/om/fakta/l.3488?l=en UK); 6 per cent of the professors were women and 94 per cent men (Högskoleverket, 2007). Of the students, 27 per cent were female and 73 per cent male; 83 per cent were participating in programmes, with 17 taking courses. (www.kth.se/dokument/om/redovisningar rapporter/ar06.pdf). Of the freshers, 17 per cent were from a working-class background and 27 per cent from an immigrant background. 41 per cent had parents with a higher level of education (Högskoleverket, 2007). We chose the Civil Engineering 
and Teacher Education and the Industrial Economy and Production programmes. Both are hard and applied disciplines with pragmatic habitus.

\section{Students}

Details of the six students interviewed for the purposes of this research - Emma, Erika, Elin, Edward, Eva and Edit - are presented in the vignettes below.

\section{Emma}

Emma is 23 years old and is studying for two degrees in the same programme: master's degrees in Teaching and Engineering. Her parents are from Finland and she is very proud of her Finnish background. When Emma and her brother were born their parents both worked at a factory in Sweden. At the age of three the children moved to live with their grandmother in Finland; when their parents separated, they moved to live in the northern part of Finland with their father. Emma started school in Finland but learnt Swedish while visiting her mother. At the age of ten she and her brother moved to live with their mother and her new family in a suburb outside Stockholm. After a short time in a public Swedish school that she found lacking in discipline, she went to a bilingual Swedish-Finnish school, which she enjoyed her time at. She was a good pupil and liked the fact that her teacher was strict, but was also engaged in teaching Emma to speak Swedish without a Finnish accent. Emma always speaks Finnish at home. In order to become independent - although she still lives with her mother and family - Emma has worked throughout all holidays since she was ten. She started HE study directly after finishing upper secondary school. Her boyfriend is a top student at KTH and inspired her to study there. She is now in her final year; while she is not a top student, she is good enough to be taking her exams a semester early. She appreciates the toughness of the teachers at KTH but dislikes the competition among students. She was very disappointed when a fellow student stole her laboratory report at the beginning of her studies, after which she found it difficult to become friends with other students. She sees herself as an honest, ambitious student who likes to learn hard facts. She wants to work as an engineer but she wants her boyfriend to start his working career before she starts hers, because family life is very important to her.

\section{Erika}

Erika is 26 years old and is in her first year of study for an Engineering MSc with Teaching. She was born and grew up in a working-class area in a middlesized city in Sweden with a Polish mother, a Swedish father and a half-brother on her mothers' side. Ini- tially her father was as a construction worker and her mother worked in a restaurant kitchen, but her father took early retirement because of illness. Erika sees herself as her father's girl. He wanted to keep her for himself and forbade her mother to speak Polish with her. When Erika was 14 her mother was diagnosed with cancer, after which they developed a closer relationship. Her mother died a short time later. Erika went to a rather poor school but managed to learn adequately. After secondary school she worked as a receptionist but wanted to give her future children a better start in life. She therefore started to study at KTH in Stockholm. When her father became ill she dropped out of studying in order to take care of him until he died. She worked at a hotel during that time. She returned to study at KTH one year before we interviewed her. In her first week she changed educational programme and missed the induction programme at KTH. Because of this, she feels like an outsider. Erika wants a career, but is not sure that engineering and/or teaching are the right choice. She has also considered joining the police force or becoming an economist. However, she feels that KTH has a good reputation as a university. She is anxious to rediscover her Polish inheritance, has started studying Polish and is searching for her Polish relatives.

\section{Elin}

Elin is 19 years old and is studying Biology at Stockholm University. She was born in Sweden and raised by her Finnish mother. She speaks Finnish as well as Swedish and says she feels like a Swede when in Finland and a Finn in Sweden. She has both Swedish and Finnish citizenship; she gained the former recently. Her mother worked as a cleaning lady before taking early retirement because of work-related injuries. Elin meets her father rarely and feels that they do not really know each other. Her mother has not been able to help her with her schoolwork since Elin was about 14. Elin envies people whose parents have studied at HE level. She wants to help others with a similar background to hers and has put up leaflets at her former school offering to help with schoolwork in Maths and Science. She has a "nerdish" interest in Biology and has watched nature programmes on TV, experimented with flowers and studied birds since she was a child. When she undertook study, she was disappointed not to have found similar "nerds" on the course. Elin thinks that she is good enough as a student. She finds it easy to learn the names of flowers and insects and feels happy when she is able to correctly classify a flower. She finds it difficult to learn abstract things and to subscribe to the social codes of student life. Elin suffers from allergies, but they are improving, and she felt relieved when she was able to eat like everybody else on a study trip during her first study year. She feels she is struggling in relation to 
who she is and how she fits in in HE. She describes a struggle between science and mythology but has discovered that she is not alone with that struggle. She also struggles with future career choices - whether she will become an academic or get an occupation. She does not want to get stuck inside the university but is afraid of having to work as a teacher. She does not know what she could do with her knowledge elsewhere.

\section{Edward}

Edward is years old and is studying for a bachelor's degree in Social Work at Stockholm University. He was born in Australia to an English mother and a Scottish father, and was raised in England. He has an ex-wife, a son and a daughter in England and an eight-year-old son in Sweden. He is the first of his extended family to study at HE level. Edward was not a top student in England and says he could not picture himself studying in England, although he feels, after his first year of study, that he is a role model for his teenagers in England. He came to Sweden because of a girlfriend and started a record shop a few days after arriving. He supports himself through study loans and savings and is doing well, but is a little bit worried about the last study year. His studies, including learning Swedish, are important to him, and he has done well. He is surprised by the variation in quality in $\mathrm{HE}$, saying that while one course was excellent, another was a disaster. From the outside, the excellent course looked likely to be extremely boring - one lecturer talked for three hours about the classics in Sociology without a pause, but really knew what he was talking about. Edward thinks that if he had been younger he would have gone into Sociology. He describes the exam in the course as very difficult, but so interesting that he wrote a whole essay in Swedish and got an $\mathrm{A}$. In the bad quality course the teacher, who was a social worker herself, was not competent at all. The course became a "flop", but when Edward tried to form a protest group he found that his student mates were products of the "individualistic era". Edward is not engaged in student life; he is "there to learn and not to drink". He separates his different lives. He has some student friends that he studies with, he sometimes meets his old music friends and he is a single father. He has no interest in mixing these lives, because "they all only have me in common and that is not enough!"

\section{Eva}

Eva is 28 years old and is in her last year of studying Biomedicine at KI. She was born and grew up in Malmö, the third-largest Swedish city, with her mother. Her parents moved to Sweden from the former Yugoslavia as labour immigrants during the 1960s. Her mother worked in the warehouse of a bakery but is now retired. She never learnt Swedish. Eva sees herself as very different from her mother. She has always been good at school, although the school she went to made her miserable. In upper secondary school she wanted to become a writer, so she started studying literature at university. She then combined university studies of different kinds with unqualified jobs. She became interested in the human body and attended a course in massage. She also applied to become a physician at KI but, as she did not get a place, she decided to study Biomedicine. Eva struggles with the academy. She sees herself and her friends as intellectuals, although they are not all academics. She studies by herself and misses co-working with other students. She is critical not of education, but of the academic context. The academic use of language is, in her opinion, a way of excluding people. She does not want to be judged and forced to market herself in the academy. She thinks that she is as good as anyone else, but nevertheless sometimes struggles with her self-confidence. She is interested in gaining new knowledge but not academic prestige. Despite this, she wants to join the doctoral programme and is struggling to get access. She envies students from other backgrounds who know how to act within the academy.

\section{Edit}

Edit is 34 years old and is studying to become a physiotherapist at KI. She was born and grew up in a middle-class family in Stockholm, with a father who came from Finland as a Jewish refugee during the Second World War and a Jewish mother from Denmark. Edit's family members speak several languages and she has relatives all over the world. Her mother died some years ago and her father is now in retirement in France. Neither of her parents studied in HE. Edit went to a French-speaking school because her family loved the country, although they did not themselves speak French. Edit had difficulties with the language and hated school. Due to this, she does not consider herself a good student. After finishing upper secondary school she worked as a waitress in a number of restaurants. After several years she got a chronic back injury and started attending physiotherapy. This was how she discovered the desire to become a physiotherapist. She joined municipal adult education and discovered that she did have a good head for studying after all. She is in her last semester and has struggled to adapt because of her injured back and her experiences of being a bad learner. She has got good support from her teachers but has trouble with being judged in exams. In the future she wants to help people suffering pain. Edit does not regard herself as an academic - she is just getting a profession, becoming something outside the academy. 


\section{ANALYSIS OF STUDENTS' STORIES}

What struggles do adult learners experience in their formation of a learning identity in HE? In the stories above we have found struggles relating to being a student in HE in general, learning, and becoming an academic versus becoming a professional. These struggles are further related to ethnicity, class, age and gender, as will be seen.

\section{Struggles related to being a student in $\mathrm{HE}$}

In Emma, Erika, Elin and Eva's stories there are examples of struggles related to how they fit into university social life. They all describe themselves as outsiders in different respects. Age does not matter; both younger and more mature female students experience problems with fitting in: Emma finds the competition hard to bear, Elin finds the social codes very difficult and for Eva issues of academic prestige are unbearable. Elin and Eva state that they envy students whose parents studied at HE level and were able to help their children in their studies. They have had to learn everything by themselves and are not at all familiar with the strategies used by students from more traditional homes.

The students who see themselves as outsiders in HE also tend to learn by themselves rather than together with other students. For the most part, Emma, Erika, Elin, Eva and Edit all study alone. Emma, Elin and Eva see themselves as good enough as students but also compare themselves to other top students. Elin thinks that she is good at learning specific things but finds it hard to absorb abstract knowledge. Edward, a mature student, is struggling with his Swedish but is surprised that it has gone so well. He is also proud that he has become an independent learner. Eva sees herself as especially good at creating knowledge but struggles with having to market herself within the academy. Edit, a mature student, struggles with physically demanding tasks due to her back injuries and is studying hard in order to handle the anxiety created by being judged in exams.

The students describe a struggle between academy and profession. Eva wants to continue on to doctoral studies and has problems with being an outsider in academia, whereas Elin is worried about getting stuck inside the academy. Elin on the one hand really likes learning biology, but on the other thinks that academic people lack knowledge about the real world. For Edit, Edward, Erika and Emma there is no struggle between academia and profession: they are studying to become professionals, not academics. Edward is very interested in sociology and argues that if he was younger he could have stayed in this area, but now he has to make his living, and has missed his opportunity. Erika is studying without being sure that she wants to become an engineer. She could continue her studies elsewhere, but feels that the fact that she is studying gives her a good reputation at this time.

\section{Struggles related to class, ethnicity, age and gender}

The students describe struggles related to their social background. In the stories told by the students, class background seems to be the most important issue, regardless of gender or ethnic background. Eva, Erika, Elin and Eva struggle to fit in in the academy and envy those with parents who have gone through HE. The social codes, academic prestige and competition feel strange to them. Edward, however, would never have had entered HE in the UK, but found it possible in Sweden.

Ethnicity-related struggles do also appear in the students' stories. Elin and Emma struggle with Finnishness versus Swedishness. They are both proud of their Finnish inheritance but live in Sweden and are not really seen by others as anything other than Swedish. They both speak Finnish and Swedish. For Erika, her Polish inheritance is something that she was not allowed to develop when her father was alive. She is now seeking it by studying Polish and searching for Polish relatives. Edward and Edit's different backgrounds seem to be integrated in being international. Edward sees himself basically as a "Stockholmer" with a multiple Anglo-Saxon background. $\mathrm{He}$ is learning Swedish in order to work as a social worker. For Edit, the international character of her family is also a natural thing, even though she found it hard to cope with going to a French school when she was a child. In Eva's case, while her mother never learnt Swedish, she does not talk about her Yugoslav background and sees herself as a Swede.

Edward, Edit and Eva describe struggles relating to age. Eva is worried about her chances of starting her doctoral studies because she thinks she is too old. For Edward the closing of the academic door relates to his age and family responsibilities. Edward and Edit see themselves as learners more than as students.

The students raise a few gender-related issues. Edward refers to the large number of women in his educational programme and notes that he could be the only male student starting the second year in his class. Elin, who finds it easier to relate to men than women, was disappointed to discover that most of her fellow Biology students were 'boring blonde girls'. Emma's desire to 'be a good girl' and prioritise her family and her boyfriend's career has provoked criticism from her fellow students at KTH. For Edit the question of gender is mainly seen in relation to her 
choice of subject for her bachelor thesis. She wants to study women because of the lack of research concerning them.

\section{Academic culture and context}

The three institutions studied (SU, KI and KTH), represent different cultures and sub-cultures. To use Becher's distinction, natural sciences are seen as pure and hard disciplines directed by the paradigm of casual explanation (exclusive habitus); classical sciences and humanities as pure and soft disciplines guided by understanding and interpretation (ambivalent habitus); technical sciences as hard and applied directed towards development and application of techniques and products (pragmatic habitus), but also hard and pure (exclusive habitus) which differs from Becher's definition showing a change at KTH to a more theoretical and research oriented discipline; and finally, applied social sciences as soft and applied with the aim to serve professional practice in interactive contexts (inclusive habitus). Even these disciplines, however, are seeking to become more research-orientated.

To a great extent, lecturers' expectations and constructions of students' identities depend on the culture to which they belong. The culture is shaped by traditions (inner culture) and new trends coming from outside, both nationally and globally (outer culture). We can see two tendencies in the way that lecturers approach their disciplines. Traditional disciplines like biology, biomedicine and engineering have a solid research orientation: the main task of lecturers and professors is clearly research. In new disciplines like social work, industrial economy and production and physiotherapy, there are clashes between professional and academic traditions. Some lecturers have worked outside the university, there are few professors, and only very few lecturers hold PhDs. Many are not involved in any research at all, but aspire to belong to the world of academia. On the one hand, this is the result of HE policy seeking to make different disciplines more research-orientated (academic); on the other hand, the same policy (expressed by the state and the labour market) states that education has to lead to a profession and occupation.

Both approaches indicate the struggles that lecturers experience. On the one hand, the traditional academic milieu does not prepare students for work outside the university; this can frustrate students and in some programmes even leads to increased drop-out levels. Lecturers try to keep students by creating new courses and approaches. They even spend external research money on developing courses and teaching. On the other hand, the disciplines connected with professions struggle with their desire to make programmes more research-orientated. For students who are instrumentally driven, research orientation does not make any sense. Thus, from the students' perspective, the traditional approach (inner discipline habitus) does not attract them. They do not want to become researchers, and are constantly concerned about occupations to which their studies can be applied (biology, biomedicine). Civil engineers, however, do not have this problem. An occupational orientation is perfect for students, but even here, lecturers can find it difficult to encourage students to think in a way that is more academic. Moreover, there is a problem regarding how to connect theory with practice, and academic thinking with occupational logic.

Chemistry lecturers teaching in the Biology programme (with its several sub-disciplines) identify themselves as researchers in a hard/pure discipline where abstract thinking is fundamental. Social work is characterised by being generally soft/applied, but also hard, especially if psychology is involved. In chemistry only male professors were interviewed; in social work mostly female lecturers with low academic positions were interviewed. Biomedicine is hard, pure and research orientated, while physiotherapy is sometimes hard/applied and sometimes soft/applied. Biomedicine is dominated by male lecturers who have the highest academic rank (professors), while the reverse is true of physiotherapy. Civil engineering is situated between hard/pure and hard/applied, but industrial economy and production is both hard/ applied and soft/applied. KTH has very few female students; as a result there is a high drop-out rate of women because - as one lecturer admitted - they are treated like men. The staff expressed a belief that women are brighter than men but lack confidence, and one female lecturer felt that she was no longer accepted by male students.

What are the staff's expectations of students? Who is a good student, according to the lecturers we have interviewed? On the Biomedicine programme, good students are those who understand, think, are active and reflective, take the initiative in their learning, take care of themselves, are responsible, interested and goal-orientated and think critically. They are also successful at coping with exams. The ideal is a good academic worker. On the Physiotherapy programme, good students possessed good prior knowledge; they were communicative, happy to take the initiative, responsible, ambitious, curious, able to function within a group and ethical. The way to support learning, said the lecturers, is to create the right conditions and take the teaching role seriously. The ideal students are those who fit in in an academic as well as a professional sense.

For lecturers in social work, good students are curious, serious and cooperative, bring with them differ- 
ent competencies, are motivated, interested, critical, open, ambitious, flexible and hard-working, good in writing and academically stringent and clear. They search for knowledge, are responsible and confident in questioning the lecturer, and seek to find new ways of thinking. For chemistry lecturers, good students are eager to learn, are motivated, committed and interested; have good prior knowledge (of mathematics), question and challeng, are curious and mature, treat their studies as an intellectual challenge, are hard-working and devote time to study, are social and active in class, work independently, develop and show progress. For both of these programmes, a good academic student is the ideal.

Civil engineers see the best students as self-independent, interested and wanting to learn, but also as happy to question themselves and others, study independently and take the initiative. Moreover, they should use their time for in-depth study, be motivated, goal-orientated but also sociable, contribute to group work and arrive with the expected prior knowledge. Successful students are well organised and disciplined. The only female lecturer in this programme says that students have a greater ability to learn before they reach the age of 27. Staff at the programme for Industrial Economy and Production consider good students as those who are motivated, work well on tasks, are good planners and listen to instruction; can discuss in groups; are goal-orientated, take time for practical tasks and exercise their language, mathematics and physics skills. Moreover, those who cope well with studies are prepared to take risks, ask questions, work well with peers, use social skills and become leaders of industry. There is a slight difference between these last two ideals - the latter is much more related to a characteristic that is important in the labour market.

We can conclude that lecturers find academic skills and abilities more important; in only a few cases do they mention social skills, and they very seldom mention students' abilities in practical tasks that are important for their job. In professional programmes, there is a strong emphasis on working together; in physiotherapy, ethical issues were highlighted.

Lecturers whom we interviewed were asked how they viewed learning. We could identify two views of learning: firstly, the knowledge and research-orientated view, that is, the preparation for understanding and developing academic discipline, and secondly, the instrumental-orientated view, seeing learning as preparation for practical issues such as solving problems, doing well in lab work, application in practice and engineering. However, these views are not easily separable but instead are part of a wider whole. Nevertheless, intellectual abilities are linked more with learning than with carrying out practical tasks.
The lecturers in biomedicine view learning as part of a wide spectrum that includes assimilation of knowledge, problem solving, contribution to knowledge, skills development and, for some, the use of these skills in practical situations. In physiotherapy, learning was seen as a matter of development, action and reaction, knowledge and the possibility of action, connected to professionalism. Lecturers emphasised self-learning, both theory and practice, and thinking for oneself. They viewed learning as the integration of all knowledge, as skills and attitudes incorporated. For some, it is simply a matter of new knowledge acquisition, but others see it also as application in practice. Learning is considered both an individual and a group process.

The lecturers in social work define learning as what happens when practice provides questions and gives answers through social practice and experience. They see students as self-learners growing through dialogue, creating their own knowledge and asking themselves questions. It is a process in which knowledge is integrated with the student's own experience. The tool for learning is conceptual apparatus and processing; they see it as a complicated process to be performed both individually and with others, as a result of which students are able to perform the required tasks. Chemistry lecturers associate learning discovery; understanding the relationship between facts, structure and solving problems; creating models; learning on one's own; active thinking and seeing connections; using data to understand and predict, asking questions rather than memorising facts; and being quick to associate things. Learning is a matter of interpreting, making observations, examining theories, understanding new combinations, understanding chemistry and developing oneself, gaining practical laboratory skills, experiencing how things function, being able to explain things and having individual interests.

The lecturers at KTH see learning as the acquisition of an academic grounding with which to understand context and the attitudes to knowledge. Moreover for them learning involves acquiring the ability to transform information into useful knowledge, that can be applied in a broad range of contexts. Learning is about integrating knowledge with one's own experience and understanding of the unknown, reflection and integration with oneself, use of knowledge, usefulness in life. The lecturers at the main campus look at their responsibilities regarding learning in the following way: I want to make students interested in a subject, to motivate them, and transmit knowledge. The motivation for learning is obvious: to raise oneself higher, to develop. That means acquiring predetermined knowledge and understanding it. Learning changes by correcting afterwards; it is more practical, systematic methodological work. Learning certain 
formulae by heart is a prerequisite in mathematics, as is solving problems. Learning a language requires the acquisition of both vocabulary and the methods and conditions of learning. Learning produces changes in the learner, in how old and new thinking work together. There is no place for trial and error in academic learning; but routine is required. Learning includes practical and theoretical abilities and is a matter of problem solving, where creativity, curiosity and skills are all required. Learning is the acquisition of new knowledge, in a new context - not repetition. The object of learning is to gain knowledge, skills and experience, and teaching helps with this.

Generally, the staff's view of learning is rich and interesting, but very academic in nature. It seems that this is an identity lecturers seek to foster and promote. However, lecturers on professional programmes see learning more as a holistic phenomenon involving all pieces of knowledge and skill.

\section{DISCUSSION}

The aim of this paper is to deepen understanding of the forming of learning identities amongst non-traditional students in HE from a student and staff perspective. As the students say, to be a non-traditional student in HE is to be an outsider, having to study alone and longing to "know how it works there". The students are afraid of failing (Quinn, 2004) and want to do well, but have difficulty and are not willing to play the overly competitive part of the academic game in order to become top students. Many want to become good professionals after their studies and are struggling with what that means (Thunborg, 2009).

Outsider feelings in HE seem to be related more to issues of class and age than ethnicity and gender; this finding supports previous research. Ethnicity and gender seem to be more related to struggles in forming identities in life more generally (Bron, Thunborg \& Edström, 2011).

With regard to the three identities previously discussed in this paper (Bron et al., 2010), Edward and Edit are examples of the multiple integrated identity; with a lot of previous life experience, they are mature, international and study to learn. Emma, Erika and Elin are examples of the floating identity, struggling with who they are, what they are supposed to be, how to learn and what they should do with their knowledge. Eva's identity is adopted. Despite her struggles, she has adopted a Swedish identity and has begun to adopt an identity in the academy, wanting to become a $\mathrm{PhD}$ student, with the focus on creating new knowledge. Age and previous life changes - for example changing career - seem to be important in the formation of a multiple integrated identity, and socialisation within the academy in the formation of an adopted identity. A floating identity could both be related to age or to being a newcomer in academia. The students seem to be in a transitional space (Winnicott, 1971), floating (Bron, 2000) and trying to find themselves within both life and academia.

Despite their differing attitudes towards their own disciplines and institutions, the lecturers whom we interviewed are socialised to traditional academy as a place for research and had their habitus formed during their own study and academic career, or even earlier if they came from an academic background. We could notice a double identity among those who had experienced work outside academia - they saw their role as a bridge between academy and practice, thus indicating a multiple integrated identity. However, even they approached learning as an academic task, in which problem solving, the acquisition of new knowledge and creative and reflexive thinking are most important. Thus, the main role of staff is socialisation into the discipline and the logic of academy. Students, especially non-traditional ones, experience a clash between staff's expectations and their own desire to go through university in order to get a ticket to the labour market.

\section{CONCLUDING REMARKS}

Non-traditional students forming an adopted identity also seem to form a learning identity of being "good students". They identify themselves with the academy generally and the norms of the institutions more specifically, and seem to have much in common with lecturers socialised in the academy and relating themselves to research. Students forming a multiple integrated identity define themselves as learners, not as students; some of them consider themselves independent learners, good in discussion and in creating knowledge, aspects also valued by the lecturers. They also seem to have much in common with the lecturers who have different experiences and see their role as a bridge between academy and practice. These are more mature students. Students forming a floating identity have difficulty defining themselves in the academy at all. They talk about themselves as "good enough" at their studies and are surprised if they do better than that. These are mostly younger, nontraditional students. Finally, we seem to have found a pragmatic identity, where students adapt to their studies as a means to the end of a future profession. They form an instrumental learning identity.

Generally, status within an academic institution is related to research orientation (hard or soft). Students' attitudes show the opposite and are more related to labour market values - that is the more applied, the more suitable for getting employment. 
There is a tendency towards an instrumentalism of students' choices and in students' learning strategies. This instrumentalism is fostered in society, through educational policy and mass media. Research and general knowledge do not have the same high status in society that they used to have.

Academic interest is not common among the students we interviewed; they simply want to gain entry into a solid profession. Study in order to get a profession could be seen as part of the working-class culture in which a job is more important than knowledge. It could, however, also be seen as part of the changed role of HE in society, where it is seen purely as a system for creating skills in order to increase national profit, and a longing for applied, technical, useful knowledge (Nussbaum, 2010). Thus, non-traditional students often show a pragmatic approach towards academic studies.

\section{REFERENCES}

Alheit, P. (n/d) The symbolic power of knowledge. Exclussion mechanisms of the university habitus' in the German HE system. (Paper not published).

Becher, T.(1987). 'Disciplinary Discourse' In: Studies in Higher Education, Vol. 12, pp. 261-274.

Becher, T. (1989) Academic tribes and territories. Intellectual enquiry and the cultures of disciplines. Milton Keynes: Open University.

Bourdieu, P. (1996, 1984). Homo academicus. Stockholm: Symposion.

Bron, A. (2000). Floating as an analytical category in the narratives of Polish immigrants to Sweden, pp. 119-132. In: Allvarlig debatt and rolig lek. En festskrift tillägnad Andrzej Nils Uggla, Uppsala: Uppsala Universitet, Centrum för multietnisk forskning.

Bron, A., Edström, E., \& Thunborg, C. (2010). Struggles in student identity - A space for poetry. Paper presented at the ESREA Life History and Biography Network conference, Life History and Biography Network, Växjö 4-7 March 2010.

Bron, A. \& Lönnheden, C. (2004). HE for Non-traditional students in Sweden- A matter of inclusion. Journal of Adult and Continuing Education. 7, (175-188).

Bron, A. \& Talerud, B. (2005). En historisk tillbakablick på vuxenlärande, s.20-34. I: Bron, A. \& Wilhelmson, L. Lärprocesser i högre utbildning. Stockholm: Liber.

Coronel Llamas, J. M. (2006). Technologies of disciplinary power in action: The norm of the "Good student". Higher Education, 52, 665-686.

Edström, E. (2009). Wanting to become something - about forming identities in Higher Education. Paper presented at the third Nordic conference on adult learning: Communication, collaboration and creativity, 22-24 April 2009, University of Southern Denmark, Odense.

Giddens, A. (1984). The Constitution of Society. Outline of the Theory of Structuration. Cambridge: Polity press.

Högskoleverket, 2007. Universitet \& Högskolor. Högskoleverkets årsrapport 2007. Stockholm: HSV, Rapport, 2007:33R.

Leathwood, C. (2006). Gender, equity and the discourse of the independent learner in higher education. Higher Education, $52,611-633$.

Mead, G.H. (1934). Mind, self, and society. From a standpoint of a social behaviourist. Chicago: University of Chicago Press.

Merrill \& Alheit (2004). Biography and narratives: Adult returners to learning. In Osborne, J. Gallacher \& Crossan, B. (Eds.) Researching widening access to lifelong learning. London: Routledge.

Merrill, B. \& West, L. (2009). Using biographical methods in social research. London: Sage.

Murphy, M. \& Fleming, T. (2000). Between Common and College Knowledge: exploring the boundaries between adult and higher education. Studies in Continuing Education, vol 22, no1,pp 77-93.

Nussbaum, M, C. (2010). Not for profit. Why Democracy Needs the Humanities. Princeton: Princeton university press.

Rapport 2009:23R. Swedish Universities \& University Collages. Short Version of Annual Report 2009. Stockholm: HSV.

Quinn, J. (2004). Understanding Working-Class “Drop-Out” from Higher Education through a Sociocultural Lens: cultural narratives and local contexts. International Studies of Education. Vol 14, no 1, pp 57-73.

Thunborg, C. (2009). Forming a relation to the body - Learning to become a physiotherapist. Paper presented at the third Nordic Conference on Adult Learning: Communication, Collaboration and Creativity, 22-24 April 2009, University of Southern Denmark, Odense.

Thunborg, C. \& Bron, A. (in press). Higher education and lifelong learning in Sweden. In: Slowey, M. \& Schuetze, H. (Eds.). Global perspectives on higher education and lifelong learner. London: Routledge. 
Thunborg, C. \& Edström, E. (2010). Changing learning identities and higher education, pp.76-87. In: Merrill, B., Monteagudo, J. G. (Eds.). Educational Journeys and Changing Lives. Adult Student Experiences. Vol. 1. Sevilla. Ėdicion digital@tres.

West, L. (1996). Beyond fragments. Adults, motivation and higher education. A biographical analysis. London: Taylor \& Francis.

Winnicott D. W. (1971). Playing and reality. London: Routledge.

www.kth.se/om/fakta/l.3488?l=en UK

www.kth.se/dokument/om/redovisningar_rapporter/ar06.pdf

www.su.se/pub/jsp/polopoly.jsp?d=3807\&a=13337 